\title{
Mission emissions
}

\author{
Meeting global, national and regional targets for greenhouse-gas emissions reduction requires \\ concerted action on several fronts.
}

When the European Union included flights into and out of Europe into its Emission Trading Scheme (ETS), China and the United States made their displeasure crystal clear. Negotiations aimed at reducing greenhousegas emissions from the aviation sector remain fraught. For reasons elaborated on by Sonja van Renssen (page 767), similar attempts to regulate emissions from international shipping through market-based mechanisms are likely to be equally fractious. Carbon dioxide emissions from shipping now stand at around 1 billion tonnes annually and are set to escalate at an alarming rate. The problem is clear, but no obvious solution is in sight. Certainly, the notion promulgated three years ago by the International Maritime Organization that emissions from shipping could be cut by nearly a third by 2020 seems unrealistic in practical terms - unless, that is, attractive financial incentives are quickly set in place. But given political wrangling, lobbying from stakeholders and the complex structure of the industry itself, the chance of a viable legislative framework being established anytime soon seems remote.

But it's not all doom and gloom on the emissions front. Following the relatively successful implementation of several regional pilot projects, China is to introduce a national emissions trading scheme. This is good news, not least because China is now the world's largest greenhouse-gas emitter.

As discussed by Alex Lo on page 765, however, China faces considerable structural hurdles as it transitions from a strictly socialist 'command and control' economy to one focused more on market-based solutions. The nation has already been moderately successful in reducing its energy intensity, which if sustained should also bring environmental benefits. But a key challenge will be to establish effective regulatory structures, such as robust monitoring and verification mechanisms. Indeed, there remains much uncertainty about China's greenhouse-gas emissions, with greatly debated discrepancies between provincial and national-level emissions statistics (Xue and Ren page 762; see also Guan et al. Nature Clim. Change 2, $672-675 ; 2012)$. In addition, overcoming resistance from provincial and municipal leaders fearful that emissions caps will constrain local economic growth will be no easy matter. Nevertheless, as Lo says, China stands to benefit economically by exploiting the fast-growing carbon finance industry and international assistance from institutions such as the World Bank.

Clearly, there is a close connection between economic activity and emissions. As Richard York explains on page 762, many models of this relationship implicitly assume that the effects of economic growth and decline on carbon dioxide emissions are symmetrical. However, by analysing cross-sectional time-series data (1960-2008) from the World Bank's World Development Indicators, York has shown that the empirical relationship is actually asymmetrical. Specifically, he found that in years of economic shrinkage, carbon dioxide emissions per capita do not decline in proportion to the amount by which they increase with economic growth. As a possible contributory explanation for this observed asymmetry, York suggests that economic growth generates durable, energy-intensive goods such as transportation networks and vehicles that remain in place and continue to generate emissions even when economic growth falters and moves into recession. As he points out, this may explain the observation made by Glenn Peters and colleagues (Nature Clim. Change 2, 2-4; 2012) that global carbon dioxide emissions fell only modestly in 2009 following the global financial crisis compared with the subsequent surge in emissions as the global economy picked up again in 2010.

York believes that his findings show that history matters, with important implications for modelling and possibly also for projections of future carbon dioxide emissions. However, he acknowledges that modelling approaches such as those that rely on capital stocks may account for the observed asymmetry. It will certainly be interesting to see how the field develops in the light of these findings.

Whatever the outcome, it is clear that we need to find more efficient ways of using energy if we are to protect the climate by reducing emissions. On page 780 , Charlie Wilson and colleagues make the case that more emphasis should be placed on 'end-use' technologies, defined as those technologies used to convert energy into final services such as heating or refrigeration, rather than energy supply. They show that efficient end-use technologies have the potential to deliver large emissions reductions and are deserving of much greater investment, in research and development for example. They argue that such technologies also "provide higher social returns on investment than energy-supply technologies" and that at present "directed innovation efforts are strikingly misaligned with the needs of an emissions-constrained world." Essentially, much of the present technological innovation in the energy sector is focused on energy supply, rather than end use.

Moving to emissions resulting from other causes, such as land-use change, it seems that Brazil needs to clean up its act when it comes to monitoring and accounting. Paulo Roberto Pagliosa and colleagues (page 764) bemoan the fact that recent changes to the Brazilian Forest Code are allowing vast areas of salt flats and increasingly other freshwater and brackish wetlands to be converted to ponds for shrimp aquaculture. And yet significant carbon dioxide emissions resulting from such land-use change as well as from shrimp production itself have not been included in Brazil's emission statistics. Given that land conversion from shrimp farming already accounts for around 1\% of Brazil's yearly carbon dioxide emissions and is likely to increase substantially, it seems paramount that these emissions are monitored and included in inventories. As Pagliosa and colleagues note, enlightened management of Brazil's coastal and interior wetlands is important not only for meeting mitigation targets but also for conservation of habitats and the ecological services they provide.

Sadly, there are other important coastal habitats around the world that are being destroyed at an alarming rate. Among the best known of these are mangroves, which are being converted for aquaculture and lost as a consequence of coastal development. Mangroves represent important nursery habitats for fisheries; they also protect from storm surges, and store large amounts of carbon in sediments and biomass. Large amounts of this carbon are emitted to the atmosphere as carbon dioxide when mangroves are destroyed, most often for profit. However, on page 773, Brian Murray discusses a study by Juha Siikamaki and colleagues (Proc. Natl Acad. Sci. USA 109, 14369-14374; 2012), who suggest that mangroves would be better protected if economic incentives were explicitly linked to carbon storage and potential rates of loss, and at a relatively modest cost $-\$ 10$ or less for each ton of carbon dioxide emissions avoided. If the scheme proves viable, that is a surely a price worth paying. 